\title{
O gênero Staelia Cham. \& Schltdl. (Rubiaceae - Spermacoceae) no Estado de Pernambuco, Brasil ${ }^{1}$
}

\author{
Elnatan Bezerra de Souza ${ }^{2}$ e Margareth Ferreira de Sales ${ }^{3}$
}

Recebido em 23/06/2003. Aceito em 02/06/2004

\begin{abstract}
RESUMO - (O gênero Staelia Cham. \& Schltdl. (Rubiaceae - Spermacoceae) no Estado de Pernambuco, Brasil). O trabalho consiste do estudo taxonômico das espécies de Staelia no Estado de Pernambuco. Quatro espécies foram registradas: S. aurea K. Schum., S. galioides DC., S. vestita K. Schum. e S. virgata (Roem. \& Schult.) K. Schum. Apresenta-se uma chave analítica para a identificação das espécies, além de descrições, comentários, ilustrações e mapa de distribuição geográfica.
\end{abstract}

Palavras-chave: Rubiaceae, Spermacoceae, Staelia, taxonomia, Brasil

ABSTRACT - (The genus Staelia Cham. \& Schltdl. (Rubiaceae - Spermacoceae) in the State of Pernambuco, Brazil). This work presents a taxonomic study of the species of Staelia present in the State of Pernambuco. Four species were found: S. aurea K. Schum., S. galioides DC., S. vestita K. Schum. and S. virgata (Roem. \& Schult.) K. Schum. A key to identify the species, descriptions, comments, illustrations and a geographic distribution map are provided.

Key words: Rubiaceae, Spermacoceae, Staelia, taxonomy, Brazil

\section{Introdução}

O gênero Staelia foi descrito por Chamisso \& Schlechtendal (1828) baseado em uma planta procedente da região tropical da América do Sul, denominada por eles de $S$. thymoides. Este gênero distinguia-se dos demais da tribo Spermacoceae pelo cálice bissépalo, pela corola infundibuliforme e pelo fruto capsular com deiscência oblíqua. O nome genérico foi uma homenagem ao Barão August Stäel von Holstein. De Candolle (1830) reconheceu o gênero descrevendo duas novas espécies: $S$. galioides e $S$. reflexa. Na mesma obra, o autor descreveu o gênero Tessiera, baseado em $T$. lanigera e $T$. lithospermoides, ocorrentes no Brasil e no México, respectivamente.

Autores como Endlicher (1838) e Bentham \& Hooker (1873) reconheceram Staelia e não aceitaram o status genérico de Tessiera, preferindo considerá-lo como sinônimo de Spermacoce L., ao lado dos gêneros Borreria G. Mey., Difragmus Presl. e Hypodematium A. Rich.

Baillon (1880) não aceitando a identidade de Staelia, incluiu o gênero na sinonímia de Spermacoce L., cujo conceito também abrangia Mitracarpus Zucc. ex Schult. \& Schult. f., Hypodematium A. Rich., Diodia L., Dasycephala DC. e Octodon Thonn. Posteriormente, Schumann (1889) restringiu o conceito de Spermacoce, retirando de sua circunscrição os gêneros Staelia, Mitracarpus e Diodia. Este autor não aceitou Tessiera, incluindo-o na circunscrição de Staelia. Reconheceu para Staelia dez espécies, sendo quatro inéditas: $S$. aurea, $S$. capitata, S. cathechosperma e $S$. vestita; três novas combinações: S. lanigera (DC.) K. Schum., S. thymbroides (Mart. \& Zucc.) K. Schum. e S. virgata (Roem. \& Schult.) K. Schum. O autor também propôs três seções para o gênero (Tessiera, Anthospermopsis e Eustaelia), tomando como base hábito, forma e textura das folhas, tipo de estilete e permanência ou não da semente nas valvas após a deiscência. Kirkbride (1997), analisando a forma de deiscência do fruto em Anthospermopsis, propôs o reconhecimento do mesmo como um gênero a parte. Outros trabalhos abordam a descrição de novas espécies ou redescrições em floras regionais (Rusby 1895; Chodat \& Hassler 1904; Benjamin 1959; 1971; Bacigalupo 1974; 1993; 1996).

Este estudo tem como objetivo o reconhecimento das espécies de Staelia ocorrentes em Pernambuco e

\footnotetext{
1 Parte da Dissertação de Mestrado do primeiro Autor

2 Coordenação de Biologia, Universidade Estadual Vale do Acaraú, CEP 62040-370, Sobral, CE, Brasil

3 Departamento de Biologia, Universidade Federal Rural de Pernambuco, CEP 52171-930, Recife, PE, Brasil (mcroton2002@yahoo.com.br)

4 Autor para correspondência: ebsouza@uvanet.br
} 
a sua respectiva distribuição geográfica no Estado.

\section{Material e métodos}

O Estado de Pernambuco está situado entre os meridianos $34^{\circ} 48^{\prime} 35^{\prime \prime}$ e $41^{\circ} 19^{\prime} 54^{\prime \prime}$ W e os paralelos 7¹5’45” e 9²8'18’’S. Com área de $98.281 \mathrm{~km}^{2}$, o Estado apresenta o maior gradiente de leste para oeste, onde se verificam as zonas fisiográficas: Litoral, Mata, Agreste e Sertão (Jacomine et al. 1973). Em termos vegetacionais, o Estado foi dividido por Andrade-Lima (1960) igualmente em quatro zonas fitogeográficas: Litoral, Mata, Caatinga e Savanas.

Considerando a diversidade fisiográfica e fitogeográfica do Estado, foram realizadas coletas no período de abril/1995 a agosto/1996. Os exemplares coletados foram herborizados segundo as técnicas convencionais (Mori et al. 1989) e depositados no herbário da Universidade Federal Rural de Pernambuco (PEUFR). A identificação das espécies foi baseada nas publicações originais, complementando-se com informações de trabalhos atualizados, além de fotografias de materiais históricos provenientes do Royal Botanic Gardens (K). Na padronização das descrições, utilizou-se a terminologia proposta por Radford et al. (1974).

Além desses materiais, foram analisados espécimes herborizados provenientes de herbários locais e de outros Estados do Brasil, designados por suas siglas conforme o Index Herbariorum (Holmgren et al. 1990): ALCB, EAC, EAN, HRB, HST, IPA, JPB, MG, PEUFR, SP, SPF, TEGB, UB e UFP.

Os dados de distribuição geográfica das espécies procederam tanto das coletas quanto das informações de herbário e da literatura especializada.

\section{Resultados e discussão}

Staelia Cham. \& Schltdl., Linnaea 3:364. 1828.

Ervas ou subarbustos perenes, raramente anuais. Caules eretos ou ascendentes, cilíndricos a quadrangulares, opostos ou alternos ao longo do eixo principal, formando ou não touceiras, às vezes curtos, rígidos e terminando mais ou menos no mesmo nível, glabros, tomentosos, velutinos, lanosos ou pubérulos. Estípulas conadas, formando uma bainha, marginada por setas, lineares ou linear-lanceoladas. Folhas opostas ou pseudoverticiladas pela presença de braquiblastos nas axilas, sésseis, lineares a estreitamente elípticas, de base atenuada e ápice agudo, de margem revoluta, herbáceas, cartáceas a coriáceas, glabras, pubérulas, lanosas a escabras. Glomérulos pauci ou multifloros, terminais e/ou axilares, inseridos na axila de duas ou três (raramente quatro) brácteas foliáceas. Flores sésseis ou subsésseis, andróginas, homógamas, hipanto adnado ao ovário. Cálice persistente, com dois lobos linearlanceolados a subulados, de margens ciliadas, geralmente com dentículos glandulares interpostos. Corola infundibuliforme, branca, tetralobada, de prefloração valvar, externamente pubérula a pubérulopapilosa, internamente com anel de pêlos moniliformes no terço inferior; lobos oval-triangulares, pubescentes no ápice. Estames quatro, exsertos, epipétalos, alternipétalos; anteras oblongas, dorsifixas, introrsas. Estilete filiforme, bífido ou capitado, exserto. Ovário turbinado, bicarpelar, bilocular, com óvulos solitários, peltados, fixos no septo interlocular; disco nectarífero íntegro. Fruto capsular com deiscência septicida e transverso-oblíqua, separando-se em duas valvas apicais, coroadas pela sépala correspondente, e uma parte basal persistente, formada pela porção inferior dos carpelos e o septo interlocular; valvas subcarenadas a carenadas, uni a trinérvias, ou sem nervuras evidentes. Sementes planoconvexas, castanho-escuras a nigrescentes, semi-elípticas, oblongas a obovais, de face dorsal microscopicamente fovéolo-papilada, e face ventral estrofiolada, com dois sulcos longitudinais profundos; embrião axial, de cotilédones ovais, albume córneo.

Gênero com cerca de 14 espécies, 12 das quais referidas para o Brasil. Em Pernambuco registram-se quatro espécies.

Chave para as espécies de Staelia no Estado de Pernambuco, Brasil

1. Brácteas três, raramente duas, 1-1,8cm compr., 2-4mm larg.; bainha estipular com três setas 1,5-2mm compr.

2. S. galioides

1. Brácteas duas, raramente três, 1,5-4cm compr., 2-7mm larg.; bainha estipular com (3)-5-15 setas $2-7 \mathrm{~mm}$ compr.

2. Lobos do cálice 1,5-2mm compr.; corola 4-6mm compr.; lâmina foliar com a face superior escabra; ramos tomentosos, vilosos a glabrescentes 3. S. vestita 
2. Lobos do cálice 2-4mm compr.; corola 6-8mm compr.; lâmina foliar com a face superior glabra ou levemente pilosa; ramos glabros a pubérulos

3. Ramo florífero glabrescente; bainha estipular com (3)-5-7 setas

1. S. aurea

3. Ramo florífero pubérulo; bainha estipular com 7-15 setas 4. S. virgata

1. Staelia aurea K. Schum., in Martius, Fl. Bras. 6(6): 77. 1889.

Fig. $1 \mathrm{~A}-\mathrm{H}$.

Ervas ou subarbustos $30-50 \mathrm{~cm}$ alt. Caules cilíndricos a subquadrangulares na base e quadrangulares no ápice, de coloração amarelo-esverdeada, pubérulos a glabrescentes; internós 0,7-3,5cm compr. Bainha estipular 1,5-1,8mm compr., pubérula nas margens; setas (3)-5-7, 2-3mm compr. Lâmina foliar $0,6-3 \times 0,2-0,4 \mathrm{~cm}$, glabra a levemente pilosa na face superior e glabra na inferior, às vezes apenas com alguns pêlos sobre a nervura central. Glomérulos 0,5-1,8cm diâm., (3)-6-(12) por ramo florífero; internós do ramo florífero 0,8-5,2cm compr., glabrescentes; brácteas da inflorescência duas, 2-3×0,2-0,4cm. Lobos do cálice 2-2,5mm compr.; dentículos do cálice dois, glandulares. Corola 6-8mm compr.; lobos 2,1mm compr., oval-triangulares. Filetes $1,3 \mathrm{~mm}$ compr.; anteras 0,8-1mm compr. Estilete 5-6mm compr. Cápsulas 1,5-1,6×1-1,2mm. Sementes 0,7-0,×0,5mm.

Espécie com distribuição restrita ao Brasil. Ocorre nas regiões Norte (sul do Pará), Centro-Oeste, Nordeste e partes do Sudeste (Andersson 1992). Em Pernambuco, a ocorrência está relacionada aos Brejos de Altitude, como os de Bezerros, Bonito, Brejo da Madre de Deus, Caruaru e Pesqueira. Nestes ambientes, as populações podem ser encontradas nas vertentes rochosas, em concavidades, onde se acumulam detritos e solo em formação. Floresce e frutifica no período de maio a outubro.

Material examinado: BRASIL. Pernambuco: Bezerros, 20/VI/1996, fl. fr., Souza 116 (PEUFR); Souza 118 (PEUFR); Bonito, 30/VII/1996, fl. fr., Souza 125 (PEUFR); Souza 126 (PEUFR); Souza 127 (PEUFR); 16/X/1996, fl. fr., Bastos-Accioly et al. 140 (PEUFR); Brejo da Madre de Deus, 26/V/1995, fl., Villarouco 84 (PEUFR); Caruaru, 14/VII/1995, fl., Melo 95 (PEUFR 19789); Pesqueira, s.d., fl., Correia 245 (UFP).

Material adicional examinado: Bahia: Barreiras, 6/III/1972, fl., Anderson et al. 36692 (UB); Caitité, 9/IV/1980, fl. fr., Harley 21101 (UB); 10/IV/80, fl. fr., Harley 21200 (UB); 15/IV/1983, fl., Carvalho et al.1753(UB); Brejinho das Ametistas, 15/IV/1983, fl. fr., Carvalho et al. 1765 (UB); Carvalho et al.1782

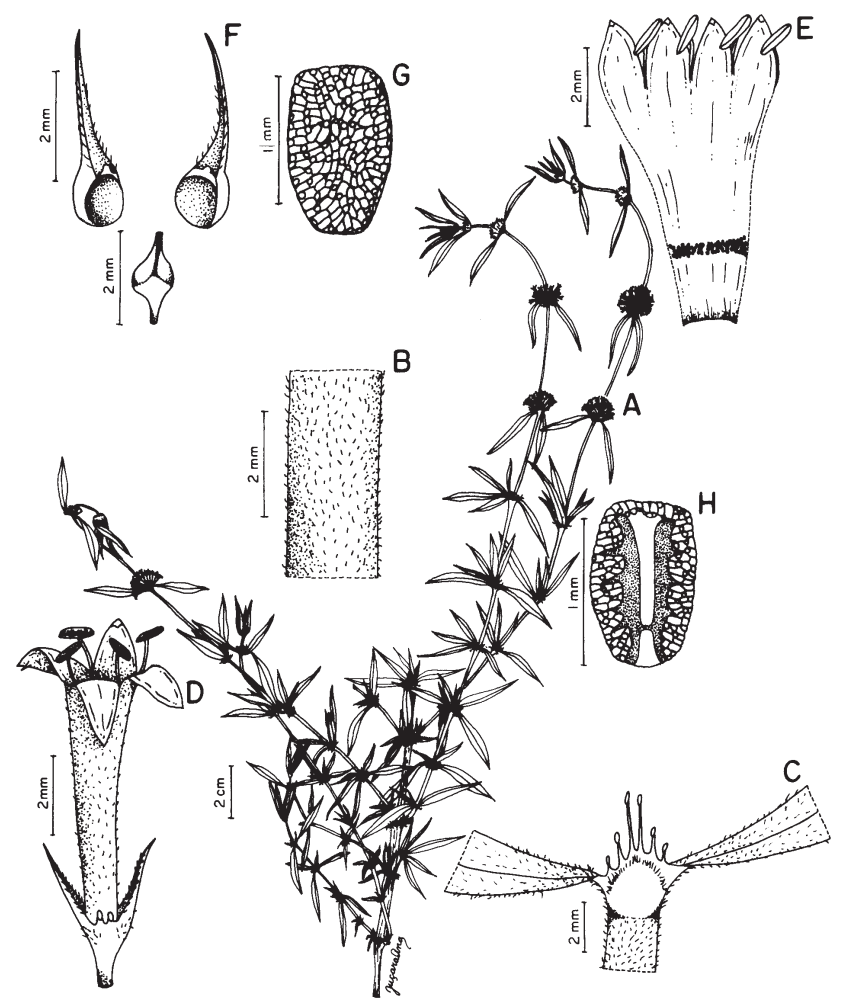

Figura 1. Staelia aurea. (Souza 118). A. Hábito. B. Seção do caule. C. Bainha estipular. D. Flor. E. Corola aberta. F. Cápsula após a deiscência. G. Semente, vista dorsal. H. Semente, vista ventral.

(UB); Cocos, 17/III/1972, fl. fr., Anderson et al. 37146 (UB); Correntina, 23/IV/1980, fl. fr., Harley 21662 (UB); Rio de Contas, 21/III/1977, fl. fr., Harley 19817 (UB); 28/III/1977, fl., Harley 20072 (UB). Ceará: Aracati, VII/1838, fl., Gardner 1706 (IPA). Piauí: Gilbués, 14/III/1979, fl. fr., Del 'Arco s.n. (TEGB 314); Oeiras, IV/1839, fl., Gardner 2192 (PEUFR). Tocantins: s.d., fl. fr., Burchell 7731 (PEUFR).

A espécie pode ser reconhecida pelas folhas glabras e pela bainha estipular com cinco a sete setas. Staelia aurea é uma espécie muito próxima de S. virgata (Roem. \& Schult.) K. Schum. De acordo com Schumann (1889), a separação entre elas estaria baseada no indumento pubérulo e na coloração cinza dos ramos floríferos de $S$. virgata e pelos ramos glabros de coloração amarelo-verde de S. aurea. Entretanto, a análise dos espécimes de Pernambuco mostrou haver variações nesses caracteres, pois os ramos floríferos podem ser glabros ou pilosos e a coloração pode variar de amarela até cinza. 
2. Staelia galioides DC., Prodr. 4: 573. 1830.

Fig. 2 A-H.

Subarbustos subcespitosos $30-70 \mathrm{~cm}$ alt. Caules cilíndricos a subquadrangulares, esfoliantes, fistulosos, pubérulos; internós 1,3-3,8cm compr. Bainha estipular $1-1,5 \mathrm{~mm}$ compr., pubescente na margem; setas três, 1,5-2mm compr., desiguais. Lâmina foliar $1-1,6-(2,7) \times 0,2-0,5 \mathrm{~cm}$, glabra em ambas as faces, às vezes com leve pubescência na base e sobre a nervura principal. Glomérulos 1,5-1,8mm diâm., 6-15-(30) por ramo florífero; internós do ramo florífero (1,5)-2,5-3,5cm compr., levemente pubérulos, às vezes glabros; brácteas da inflorescência três, raramente duas, 1-1,8×0,2-0,4cm. Lobos do cálice 1,5-2,1mm compr.; dentículos do cálice, um ou dois, glandulares. Corola 4-7mm compr.; lobos $2 \mathrm{~mm}$ compr., oval-triangulares. Filetes $1,5-1,8 \mathrm{~mm}$ compr.; anteras de $1 \mathrm{~mm}$ compr. Estilete 6-8mm compr.; ramos do estilete revolutos. Cápsulas 1,5-2×1-1,2mm. Sementes $0,8-1 \times 0,5 \mathrm{~mm}$.

A espécie apresenta distribuição exclusiva no Brasil. Ocorre na região Centro-Oeste, em Goiás, e no Nordeste, em Alagoas, Bahia, Pernambuco e Piauí. É provável que sua distribuição seja mais ampla, alcançando os outros Estados do Nordeste. Em Pernambuco, a ocorrência abrange duas áreas bem definidas: o litoral sul, envolvendo as restingas de Ipojuca (Porto de Galinhas e Serrambi), Rio Formoso (Tamandaré) e São José da Coroa Grande; e os terrenos sedimentares da Chapada de São José em Buíque, município localizado a $285 \mathrm{~km}$ do litoral. Floresce e frutifica ao longo do ano.

Material examinado: BRASIL. Pernambuco: Buíque, 15/VI/1995, fl. fr., Figueiredo 75 (PEUFR); 6/V/1995, fl., Andrade 45 (PEUFR); 15/VI/1995, fl., Andrade et al. 75 (PEUFR); 17/VI/1994, fl. fr., Costa e Silva 253 (PEUFR); 18/VII/1994, fl. fr., Rodal 257 (PEUFR); 19/VI/1994, fl. fr., Miranda et al. 1770 (HST); 18/X/1995, fl. fr., Félix et al. s.n. (HST); Ipojuca, III/1958, fl. fr., Sarmento s.n. (PEUFR 115); 29/V/1996, fl. fr., Souza 109 (PEUFR); Souza 110 (PEUFR); 29/V/1996, fl. fr., Souza 113 (PEUFR); Rio Formoso, 26/II/1997, fl. fr., Souza 158 (PEUFR); 26/VIII/1954, fl. fr., Falcão 791 (IPA); São José da Coroa Grande, 8/III/1996, fl. fr., Souza 95 (PEUFR); 26/II/1997, fl. fr., Souza 159 (PEUFR).

Material adicional examinado: Alagoas: Piaçabuçu: III/1838, fl fr., Gardner 1335 (PEUFR). Bahia: Belmonte, 7/VII/1966, fl. fr., Belém \& Pinheiro 2517 (UB); Camaçari, fl. fr., Ribeiro s.n. (ALCB27427); 14/VII/1983, fl. fr., Bautista \& Pinto 837 (MG, HRB); Castro Alves, VII/1952, fl. fr., Pinto s.n. (PEUFR

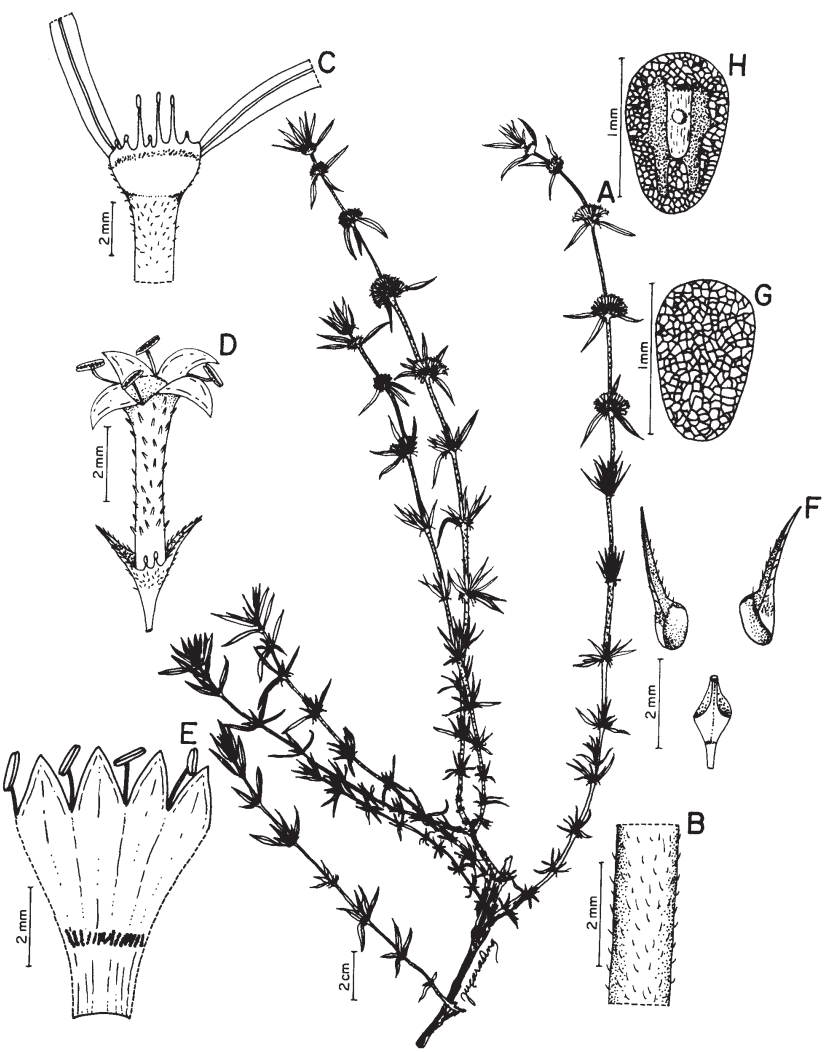

Figura 2. Staelia galioides (Souza 158). A. Hábito. B. Seção do caule. C. Bainha estipular. D. Flor. E. Corola aberta. F. Cápsula após a deiscência. G. Semente, vista dorsal. H. Semente, vista ventral.

7105); Correntina, 25/IV/1980, fl. fr., Harley 21752 (UB); Morro do Chapéu, 2/III/1977, fl. fr., Harley 19288 (UB); Ribeira do Pombal, 19/V/1981, fl. fr., Pinto 131 (MG); São Gonçalo, 15/XI/1975, fl. fr., Costa s.n. (ALCB4125); Santa Cruz de Cabrália, 31/X/1966, fl. fr., Belém \& Pinheiro 2765 (UB). Goiás: Santa Rita, IV/1837, fl. fr., Pohl 2013 (PEUFR). Piauí: Piripiri, 1/V/1978, fl. fr., A. B. Souza s.n. (UB, TEGB).

A espécie pode ser reconhecida pelo hábito subcespitoso, pelos ramos pubérulos, pela bainha estipular com três setas e por três, raramente duas, brácteas. Estas características a diferenciam de S. reflexa DC. (não ocorrente em Pernambuco), que apresenta bainha estipular com mais de quatro setas e internós bem mais curtos.

3. Staelia vestita K. Schum., in Martius, Fl. Bras. 6(6): 78. 1889.

Fig. 3 A-H.

Subarbustos perenes $30-70 \mathrm{~cm}$ alt. Caules nodosos, subquadrangulares na base e quadrangulares no ápice, de coloração amarelo-esverdeada, cinza a castanha, tomentosos, vilosos a glabrescentes; internós $1-4 \mathrm{~cm}$ 
compr. Bainha estipular 1,5-2mm compr., pubescente na margem superior; setas 5-(7), 2-5mm compr. Lâmina foliar 1,5-3,5×0,2-0,7cm, escabra na face superior e glabra na face inferior, às vezes com pilosidade sobre a nervura principal. Glomérulos 1-1,8cm diâm., 5-6-(8) por ramo florífero; internós do ramo florífero $0,8-2,8 \mathrm{~cm}$ compr., tomentosos a glabrescentes; brácteas da inflorescência duas, raramente três, 1,5-2,2×0,4-0,7cm. Lobos do cálice (1,5)-2mm compr.; dentículos do cálice 1-3, glandulares. Corola 4-6mm compr.; lobos 2mm compr., ovais. Filetes de $1 \mathrm{~mm}$ compr.; anteras 0,8-0,9mm compr. Estilete 5-6 compr. Cápsulas 1,2×1,5mm. Sementes 0,5-1×0,5mm.

A espécie apresenta distribuição exclusivamente no território brasileiro, tendo sido citada originalmente por Schumann (1889) para Piauí (Oeiras) e Goiás (Cavalcante). A distribuição abrange as regiões CentroOeste, no Mato Grosso e Goiás, e Nordeste, na Bahia, Piauí e Pernambuco, sendo esta a primeira referência da espécie para o Estado. Em Pernambuco, os espécimes foram coletados no agreste, nos Municípios de Garanhuns e Angelim, no limite sul do Planalto da Borborema. Habita escarpas úmidas, em áreas elevadas, nos Brejos de Altitude, em solos arenoargilosos. O número reduzido de exsicatas examinadas para Pernambuco não permite precisar o período de floração e frutificação de $S$. vestita. Os indivíduos coletados foram encontrados com flores e frutos no mês de março.

Material examinado: BRASIL. Pernambuco: Garanhuns, 8/III/1996, fl. fr., Souza 93 (PEUFR); Angelim, fl. fr., Souza 94 (PEUFR).

Material adicional examinado: Bahia: Barreiras, 30/I/1978, fl. fr., Fernandes \& Matos s.n. (EAC3652); São Inácio, 24/II/1977, fl. fr., Harley 18981 (UB). Goiás: s.d., fl. fr., Burchell 7989 (PEUFR). Mato Grosso: Porto Esperança, fl. fr., Kuhlmann s.n. (SP141124). Piauí: Oeiras, IV/1939, fl. fr., Gardner 2187 (PEUFR).

S. vestita foi descrita por Schumann (1889), com base em três materiais distintos: Gardner 2187, referido para o Piauí (Oeiras); Burchell 7989, citado para uma localidade de Goiás, entre a capital e Cavalcante; e Martius s.n., de procedência desconhecida. O exame das fotografias dos dois primeiros materiais históricos, mostrou serem dois espécimes bem similares. É uma espécie relativamente bem delimitada, podendo ser identificada pela bainha estipular geralmente com cinco setas, pelas folhas escabras na face superior e pelos caules quadrangulares, tomentosos, vilosos a glabrescentes.

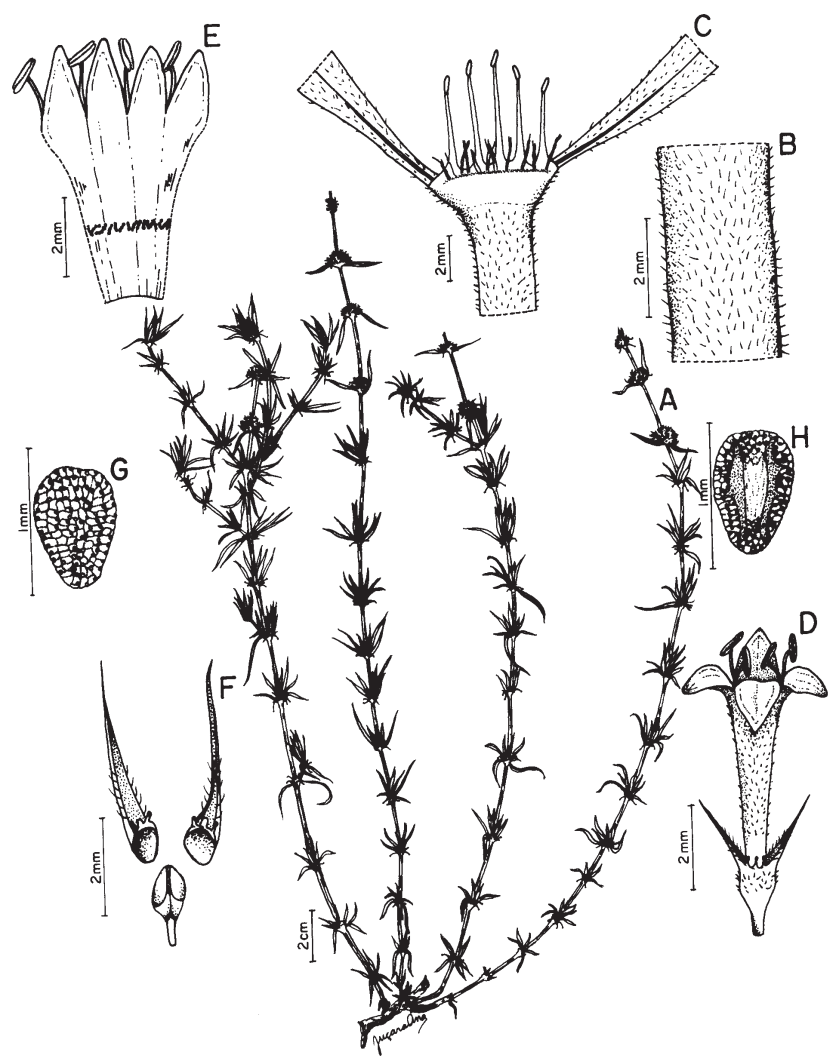

Figura 3. Staelia vestita (Souza 93). A. Hábito. B. Seção do caule. C. Bainha estipular. D. Flor. E. Corola aberta. F. Cápsula após a deiscência. G. Semente, vista dorsal. H. Semente, vista ventral.

4. Staelia virgata (Roem. \& Schult.) K. Schum., in Martius, Fl. Bras. 6(6): 76. 1889.

Spermacoce virgata Willd. ex Roem. \& Schult., Syst. Veget. 3: 281, 531. 1818; Mant. 3: 205. 1827.

Fig. 4 A-G.

Subarbustos ramosos, suberetos, $40-130 \mathrm{~cm}$ alt., ramificados a partir da base. Caules delgados, cilíndricos na base e tetrágonos no ápice, pubérulos, com pêlos recobrindo principalmente os ângulos; internós 2-6cm compr. Bainha estipular 1,5-2mm compr., pubérula; setas 7-15, 0,5-7mm compr. Lâmina foliar 2,2-4,7×0,3-0,9cm, face superior glabra a levemente pilosa, face inferior glabra. Glomérulos 1-1,4cm diâm., (4)-6-12-(25) por ramo florífero; internós do ramo florífero 2-3,5-(5,9)cm compr., pubérulos; brácteas da inflorescência duas ou raramente três, 2,2-4,1×0,3-0,7cm. Lobos do cálice 2-4mm compr., geralmente com dois ou três dentículos glandulares interpostos. Corola 6-7mm compr.; lobos 1,5-2mm compr., oval-triangulares. Filetes 1,1-1,3mm compr.; anteras 0,8-1mm compr. Estilete 6,5-7,1mm compr., bífido; ramos do estilete ca. $0,5 \mathrm{~mm}$ compr. 
Cápsulas 1-1,5×1-1,2mm. Sementes 0,9-1,1×0,5mm.

S. virgata é a espécie mais amplamente distribuída entre as estudadas. Sua área de ocorrência abrange todo o Brasil, parte dos territórios do Peru, Bolívia, Paraguai até o norte da Argentina. No Brasil, sua distribuição envolve todas as regiões, desde o Amazonas (Bacia do Rio Negro e leste do Rio Purus), Bahia, Ceará, Maranhão, Pará, Paraíba, Pernambuco, Piauí até os Estados da Região Sul (Andersson 1992). Em Pernambuco, a espécie está distribuída na região litorânea e da mata, nos Municípios de Goiana, Recife e São Vicente Férrer. Penetra para o oeste, ocorrendo em vários municípios do agreste, em Bezerros, Bonito, Gravatá, Itambé e Taquaritinga do Norte. Ocorre também no sertão, nos Municípios de Afrânio, Parnamirim, Santa Maria da Boa Vista, Tacaratu e Triunfo. Habita em diferentes formações vegetais, desde a Mata Atlântica até a Caatinga, quase sempre em solos areno-argilosos. Florece e frutifica no período de janeiro a agosto.

Material examinado: BRASIL. Pernambuco: Afrânio, 23/IV/1971, fl. fr., Heringer et al. 315 (PEUFR; UB); 23/IV/1971, fl., Heringer et al. s.n. (IPA19185); Bezerros, 30/VII/1996, fl. fr., Souza 130

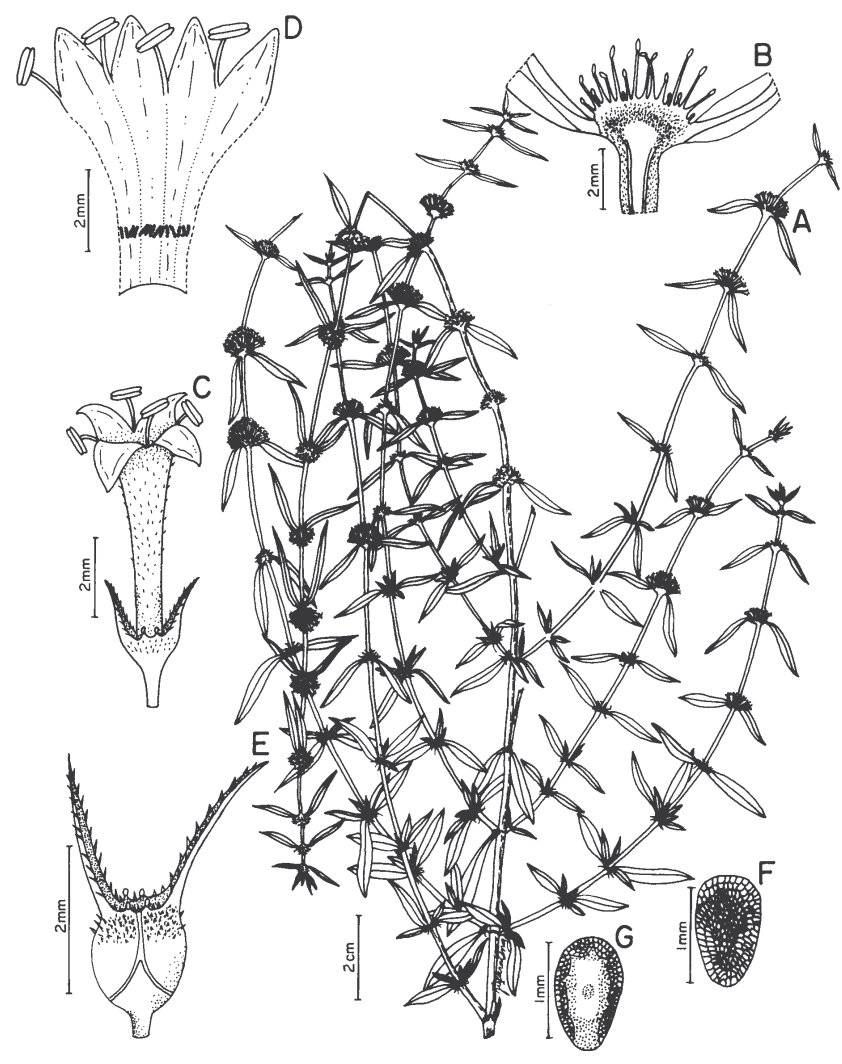

Figura 4. Staelia virgata (Souza 137). A. Hábito. B. Bainha estipular. C. Flor. D. Corola aberta. E. Cápsula. F. Semente, vista dorsal. G. Semente, vista ventral.
(PEUFR); Bonito, 9/II/1996, fl. fr., Silva 153 (PEUFR); Goiana, 31/I/1997, fl. fr., Souza 154 (PEUFR); Gravatá, 20/VIII/1996, fl. fr., Souza 142 (PEUFR); VII/1926, fl., Pickel 1128 (IPA); Itambé, 30/VIII/1996, fl. fr., Bastos-Accioly et al. 137 (PEUFR); 25/VIII/1952, fl., Magalhães s.n. (IPA12596); IX/1937, fl., Vasconcelos Sobrinho s.n. (IPA522); Maraial, 21/X/1997, fl. fr., Siqueira-Filho \& Baracho s.n. (UFP); Parnamirim, I/1985, fl. fr., Araújo 104 (IPA, UB); Petrolina, 26/VII/1984, fl., Pinto 149 (IPA); 8/IV/1983, fl., Fotius 3414 (IPA); Recife, 27/X/1995, fl. fr., Souza 29 (PEUFR); Souza 30 (PEUFR); 7/VI/1996, fl. fr., Souza 114 (PEUFR); Souza 115 (PEUFR); Santa Maria da Boa Vista, 29/IV/1971, fl., Heringer et al. 393 (PEUFR; UB); São Vicente Férrer, 31/X/1995, fl. fr., Souza 40 (PEUFR); Tacaratu, 29/V/1997, fl., Bastos-Accioly 187 (PEUFR); Taquaritinga do Norte, 1/VIII/1996, fl. fr., Souza 137 (PEUFR); 2/VIII/1996, fl. fr., Souza s.n. (PEUFR); Triunfo, 26/II/1986, fl., Lima \& Gallindo 102 (IPA); sem indicação de localidade, 2/VII/1979, fl. fr., Fernandes s.n. (EAC6667).

Material adicional examinado: Bahia: Barreiras, 6/III/1972, fl., Anderson et al. 36692 (UB); Belmonte, 5/I/1981, fl., Carvalho \& Gatti 412 (UB); Camaçari, 19/XI/1981, fl. fr., Bautista et al. 517 (UB); Rio de Contas, 28/III/1977, fl., Harley 20072 (UB); Santo Sé, 5/I/1990, fl., Miranda \& Esteves 94 (PEUFR); São Inácio, 26/II/1977, fl., Harley 19087 (UB). Ceará: Granja, 27/VI/1984, fl. fr., Fernandes s.n. (EAC12716); 26/VIII/1977, fl. fr., Fernandes \& Lima s.n. (EAC3472); Reriutaba, 25/V/1981, fl. fr., Fernandes \& Martins s.n. (EAC10323); Santa Quitéria, 7/VII/1956, fl. fr., Fernandes s.n. (EAC1621); Sobral, 19/VII/1974, fl. fr., Fernandes s.n. (EAC2461). Maranhão: Barra do Corda, 28/I/1977, fl. fr., Eiten 519 (UB); São Raimundo das Mangabeiras, 15/III/1962, fl. fr., Eiten \& Eiten 3648 (UB). Pará: Santarém, XI/1828, fl. fr., Riedel 1538 (PEUFR). Paraíba: Areia, 1/X/1994, fl. fr., Souza s.n. (EAC21698); 17/X/1988, fl., Félix \& Dorneles 1641 (EAN); 28/XI/1980, fl., Fevereiro et al. 136 (EAN); Camaratuba, 21/VIII/1941, fl., Xavier s.n. (JPB230); Campina Grande, 29/IX/1986, fl. fr., Fernandes \& Matos s.n. (EAC14781). Lagoa Seca, 27/VI/1980, fl., Agra 293 (JPB); Mamanguape, 4/IV/1989, fl., Félix 3609 (JPB); 17/V/1989, fl., Félix et al. 2021 (JPB; EAN); 13/VI/72, fl., Xavier s.n. (JPB3248); 6/III/1990, fl., Félix \& Santana 2759 (EAN); 30/VIII/1989 (fl.), Félix \& Santana s.n. (EAN5498); 4/IV/1989, fl., Félix 3609 (EAN); 24/IV/1990, fl., Félix \& Santana 
2891 (EAN); Patos, 14/V/1982, fl., Miranda \& Moura 113 (JBP). Piauí: Buriti dos Lopes, 31/V/1979, fl. fr., Castro \& Nunes s.n. (EAC6258). Rio Grande do Norte: Pirangi do Sul, 8/IX/1953, fl., Tavares 241 (HST).

Staelia virgata distingue-se por apresentar sépalas de $2-4 \mathrm{~mm}$ compr. e duas brácteas subentendendo os glomérulos do ramo florífero. A análise dos exemplares coletados em Pernambuco revela a existência de dois padrões morfológicos. O primeiro padrão corresponde às populações que habitam a Caatinga, e se caracteriza pelo hábito pouco ramificado, com 20 a 30cm alt. e com (4)-6-12 glomérulos por ramo florífero. O segundo padrão está circunscrito às áreas de Mata Atlântica e Brejos de Altitude. Neste caso, os indivíduos têm 0,4-1,3m alt., hábito mais ramificado e ramos floríferos com 10-25 glomérulos. Esses padrões morfológicos provavelmente refletem os condicionantes ambientais das áreas habitadas pela espécie.

Com base nos dados obtidos, verificam-se quatro espécies de Staelia no Estado de Pernambuco, das quais $S$. vestita constitui uma nova citação. Foram observados em Pernambuco três padrões de distribuição geográfica para as espécies de Staelia (Fig. 5). As populações de S. galioides apresentam distribuição disjunta nas restingas e nos chapadões areníticos, enquanto $S$. aurea e $S$. vestita distribuem-se exclusivamente nos Brejos de Altitude. Staelia virgata é a espécie mais amplamente distribuída, ocorrendo em diferentes formações vegetais, desde a Mata Atlântica e a vegetação dos tabuleiros do litoral norte, passando pelos Brejos de Altitude até a Caatinga, na zona semi-árida.

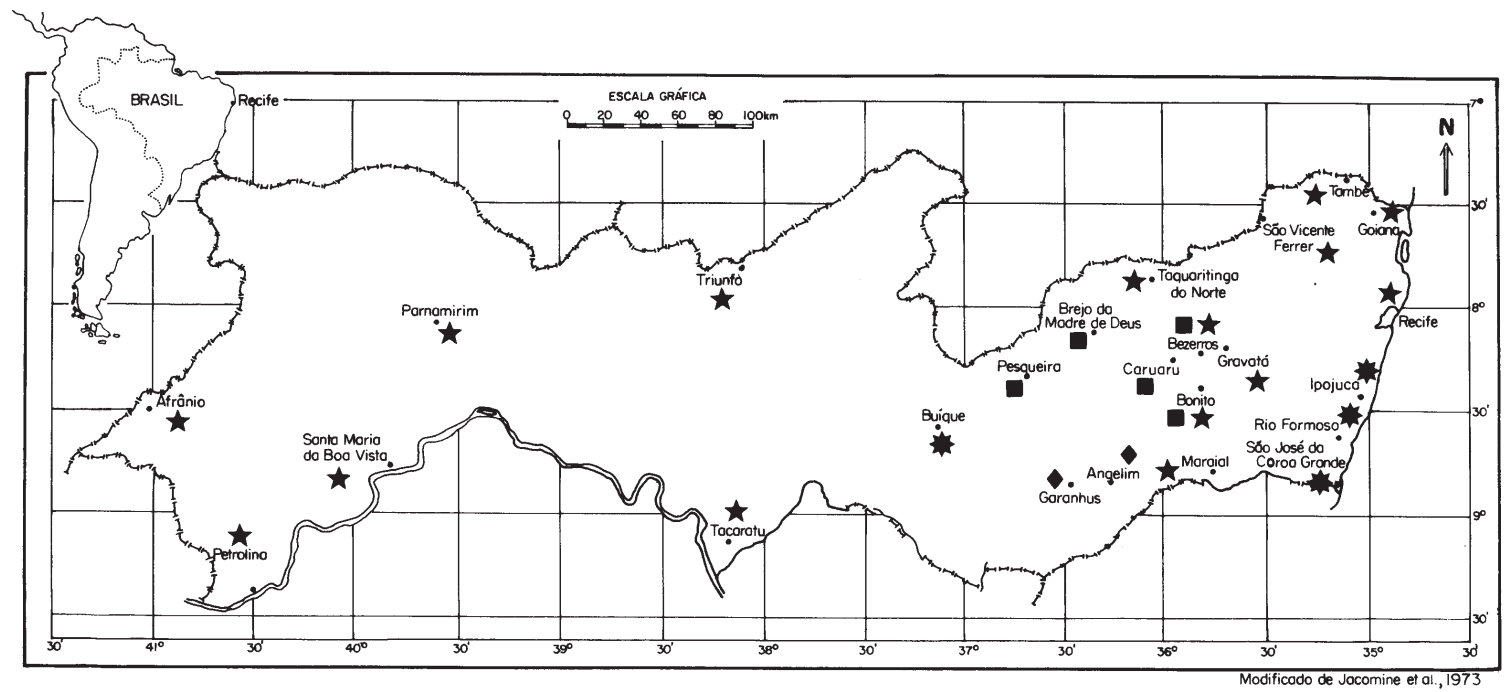

Figura 5. Distribuição das espécies de Staelia no Estado de Pernambuco. $\mathbf{\square}=$ S. aurea; $*$ = S. galioides; $\bullet=$ S. vestita; $\star=$ S. virgata .

\section{Agradecimentos}

Os autores agradecem às pesquisadoras Maria Regina de Vasconcelos Barbosa, Carmen Sílvia Zickel, Maria Jesus Nogueira Rodal e Luiza Sumiko Kinoshita, pelas críticas e sugestões; ao Dr. Simon Mayo e à Dra. Daniela Zappi, do Royal Botanic Gardens (K), pelo envio das fotografias de materiais históricos; ao Prof. Gonçalo Mendes da Conceição, da Universidade Estadual do Maranhão (UEMA), pelas sugestões e apoio logístico; à Francisca Simões Cavalcanti, pelo apoio junto ao Herbário Prisco Bezerra (EAC); à bióloga Juçara Bastos-Accioly, pela confecção dos desenhos do hábito e pelo traço em nanquim; ao
Conselho Nacional de Desenvolvimento Científico e Tecnológico (CNPq), pelo apoio financeiro.

\section{Referências bibliográficas}

Andersson, L. 1992. A provisional checklist of Neotropical Rubiaceae. Scripta Botanica Belgica 1: 1-230.

Andrade-Lima, D. 1960. Estudos fitogeográficos de Pernambuco. Arquivos do Instituto de Pesquisas Agronômicas 5: 305-341.

Bacigalupo, N. M. 1974. Rubiaceae. In: A. Burkart (ed.). Flora Ilustrada de Entre Rios. Buenos Aires, INTA 6(6): 3-50.

Bacigalupo, N.M. 1993. Rubiaceae In: A.L. Cabrera (ed.). Flora de la Provincia de Jujuy - Republica Argentina. Buenos Aires, INTA 13(9): 375-437. 
Bacigalupo, N.M. 1996. Flora del Vale de Lerma. Aportes Botanicos de Salta 4(3): 1-52.

Baillon, H.E. 1880. Histoire des plantes, Paris: L. Hachette et Cie. v.7, p. 262-266.

Benjamin, D.S. 1959. Rubiaceae da cidade do Rio de Janeiro I - Tribo Spermacoceae. Rodriguésia 33-34: 241-162.

Benjamin, D.S. 1971. Estudo das Rubiaceae Brasileiras III Cinco novas espécies da Tribo Spermacoceae. Rodriguésia 38: 253-260.

Bentham, G. \& Hooker, J.D. 1873. Genera plantarum, London: Lovell Reeve \& Co., Williams \& Norgate, v.2, pt. 1, p. 142-148.

Chamisso, L.A. \& Schlechtendal, D F.L. 1828. De plantis in expeditione speculatoria Romanzoffiana observatis. Linnaea 3(4): 338-366.

Chodat, R.H. \& Hassler, E. 1904. Plantae hasslerianae [Mitracarpus]. Bulletin Herbier Boissier 4: 190.

De Candolle, A.P. 1830. Prodromus systematis naturalis regni vegetabilis, Paris: Treuttel et Würtz, v.4, p. 571-574.

Endlicher, S.L. 1838. Genera plantarum, Wien: Friedrich Beck.; pt. 6-7, p. 527-529.
Holmgren, P.K.; Holmgren, N.H. \& Barnett, S.C. 1990. Index herbariorum. Part. 1: The herbaria of the world. New York, New York Botanical Garden.

Jacomine, P.K.T.; Almeida, J.C. \& Medeiros, L.A.R. 1973. Levantamento exploratório - reconhecimento de solos do Estado de Pernambuco. Boletim Técnico 1(26). Superintendência do Desenvolvimento do Nordeste, Recife, PE.

Kirkbride, J.H. 1997. Manipulus rubiacearum VI. Brittonia 49: 354-379.

Mori, S.A.; Silva, L.A.M.; Lisboa, G. \& Coradin, L. 1989. Manual de manejo do herbário fanerogâmico. 2 ed. Ilhéus, Centro de Pesquisas de Cacau.

Radford, A.E.; Dickson, W.C. \& Massey, J.R. 1974. Vascular plant systematics. New York, Harper \& Row Publishers.

Rusby, H.H. 1895. On the collections of Mr. Miguel Bang in Bolivia. Memoirs of Torrey Botanic Club 4(3): 209.

Schumann, K. 1889. Rubiaceae In: K.F.P. Martius (ed.). Flora Basiliensis, Monachii, v.6, pt. 6, p. 71-81. 